\title{
Quality Assurance, Relevance and Institutionalization of Continuous Assessment Implementation as Perceived by Lecturers and Students in Nigeria Universities
}

\author{
Adodo Sunday Olufemi \\ Science and Technical Education Department, \\ Adekunle Ajasin University, Akungba Akoko \\ P.M.B 001, Ondo State, Nigeria. \\ E-mail address: so_adodo@yahoo.com,Sunday.adodo@aaua.edu.ng
}

\section{Doi:10.5901/jesr.2013.v3n3p253}

\begin{abstract}
This paper investigated the perception of lecturers' and students about the relevance and quality assurance of continuous assessments as currently practiced in Nigeria universities. Three Universities and a degree awarding tertiary institution in Ondo state were selected for the study. A total of 240 subjects comprising 104 lecturers and 136 Undergraduates (not below 300) level selected through Stratified random sampling techniques were used for the study. Descriptive statistics and t-test were employed to analyze the hypothesis generated for the study. Results of the analysis shows the quality assurance of the programme implementation in Nigeria Universities. Appropriated recommendations were made based on the result of the finding.
\end{abstract}

Keywords: Continuous Assessment (CA), relevance (utility-value); Cumulative Grade Point Average (CGPA); Perception, Quality Assurance, Institutionalize

\section{Introduction}

In order to evaluate the new educational system, one policy that cuts across all educational levels through out Nigeria is that on continuous assessment. In section 1 of the National Policy on Education (revised 2004), which deals with the philosophy and goals of education in Nigeria, paragraph $9(\mathrm{~g})$ states that "educational assessment and evaluation shall be liberalized by their being based in whole or in part on continuous assessment of the progress of the individual" (p.9). This statement is well amplified in subsequent sections of the document dealing with Primary Education (Section 4), Secondary Education (Section 5), Tertiary Education and finally in Section 12 which deals with the Planning, Administration and Supervision of Education. The repeated emphasis being placed on continuous assessment is a clear evidence of its importance. Hence, it has attracted the ate ntion of scholars and educationist across literature.

The National Steering Committee on Continuous Assessment in Nigeria Schools led by Professor Yoloye regards continuous assessment as a method of ascertaining what a child gains from schooling in terms of knowledge, industry and character development, taking into account all his/her performances in tests, assignments, projects and other educational activities during a given period of term, year, or during the entire period of an educational level (Ipaye, 1995). It is also a method of using the recorded performances of each pupil to help him or her improve on his or her achievement through guidance. According to Mary Esere and Adeyemi quoting Ezewu and Okoye (1986), continuous assessment refers to a systematic and objective process of determining the extent of a student's performance in all the expected changes in his behaviour, from the day he enters upon a course of study and a judicious accumulation of all pieces of information derived from this purpose with a view to using them to guide and shape the student and to serve as basis for making important decisions about the child. In other words, continuous assessment should be systematic, comprehensive, cumulative and guidance oriented

Continuous assessment practice in many schools according to Gbore, Abe and Adodo (2011) quoting Masters and Evans (1986), is a process of collecting and recording marks at various times during a course so that they can be brought together and summed to obtain a total or cumulative score at the end of the course but Ojerinde and Falayajo (1981) examined continuous assessment in a broader and more encompassing manner by defining it as a mechanism whereby the final grading of a student in the cognitive, affective and psychomotor domains of behaviour takes into account, in a systematic way, of all his performances during a given period of schooling. This definition did not only 
consider the grading of cognitive domain alone but also the affective and the psychomotor domains of the child's behaviour are included in the final grading for the purpose of decision making.

\section{Different kinds of assessment activities}

There are many different kinds of assessment activities that can be given to learners to find out what they know and can do. Assessment activities have different purposes and may ask learners to do different things. Some assessments ask learners to recall information while others emphasize processes such as analyzing, constructing or showing a skill. The table below shows some of the different types of assessment activities and how they are usually used.

Table 1. Types of assessment activities

\begin{tabular}{|c|c|c|c|}
\hline $\begin{array}{c}\text { Activities } \\
\text { Commonly Used for } \\
\text { Exams and Testing }\end{array}$ & \multicolumn{3}{|c|}{$\begin{array}{l}\text { Activities Commonly Used for } \\
\text { Continuous Assessment }\end{array}$} \\
\hline $\begin{array}{c}\text { Selected Response } \\
\text { Questions }\end{array}$ & $\begin{array}{c}\text { Brief Constructed } \\
\text { Response Activities }\end{array}$ & \multicolumn{2}{|c|}{ Constructed Response Activities } \\
\hline $\begin{array}{l}\text { - Multiple choice } \\
\text { questions } \\
\text { - True and False } \\
\text {-Matching }\end{array}$ & $\begin{array}{l}\text { - Fill in the blank } \\
\text { - Short answer } \\
\text { - Label a drawing }\end{array}$ & $\begin{array}{l}\text { Performances } \\
\text { - Oral presentation } \\
\text { - Dance/movement } \\
\text { - Science activity } \\
\text { - Athletic skill } \\
\text { - Dramatic reading } \\
\text { - Role play • Debate } \\
\text { - Song • Practical test } \\
\text { - Interviews of learners }\end{array}$ & $\begin{array}{l}\text { Products } \\
\text { - Illustration or drawing } \\
\text { - Invented dialogues } \\
\text { - Making models } \\
\text { - Essay/composition } \\
\text { - Report } \\
\text { - Project }\end{array}$ \\
\hline
\end{tabular}

Source: Continuous Assessment: A Practical Guide for Teachers from United States Agency for International Development (USAID)

\section{Why should we use continuous assessment in the classroom?}

According to Joy du Plessis Diane Prouty Jane Schubert Mona Habib Eileen St. George (2003) Support for Continuous Assessment: A Practical Guide for Teachers from United States Agency for International Development (USAID)Bureau for Economic Growth, Agriculture and Trade Office of Education Contract ( 2003) the reasons for using continuous assessment are as follows To find out what students know and can do, to gain confidence in what we say our students know, to provide all children with opportunities to show what they know and can do. to promote learning for understanding,. to improve teaching. to let the students know how well they are progressing in their own learning. to let parents know how their children are progressing ,to help determine what kind of remediation and enrichment activities to provide, and to identify which students need assistance. and to lead to overall evaluation.

\section{What is the difference between continuous assessment and exams?}

On the difference between exams and continuous assessment, Some think of these two terms as part and parcel of each other. Continuous assessment is ongoing and is based on observations of what students are doing. Examinations are one way of assessing learners but they are only a "snapshot of the learner." Continuous assessment is like having many "snapshots" of the learner. Continuous assessments and examinations contribute to the evaluation of a child's learning. In some places educators refer to evaluation in the same way we are referring to assessment. This is usually the case when evaluation is part of a lesson plan and comes at the end of the lesson. In using continuous assessment to determine if a student has completed the required grade or course successfully. Continuous assessment helps teachers to evaluate the learner's performance. 
Table 2. Compares continuous assessment with exams.

\begin{tabular}{|l|l|}
\hline \multicolumn{1}{|c|}{ Continuous Assessment } & \multicolumn{1}{c|}{ Exams } \\
\hline Ongoing in the classroom throughout the year & Usually at the end of a unit, semester, term, year or cycle \\
\hline Many different tasks & One exam or few tests per subject \\
\hline Carried out by the teacher & Can be administered by someone other than the teacher \\
\hline May be developed by the teacher & Often written by persons other than the classroom teacher \\
\hline Marked by teacher & Often marked by persons other than the classroom teacher \\
\hline Teachers use assessment results to improve his/her teaching & Don't help teacher to identify learner weaknesses \\
\hline Are connected to the syllabus being taught & May not always be connected to what is taught \\
\hline
\end{tabular}

Alonge (2004) argued that continuous assessment shares formative evaluation features because it is periodic. According to him, it requires that results of such periodic evaluation should also form part of the final assessment of the individual student. Though, Oladunni (1998) categorically confirmed that it is obligatory by the policy of government that certificates must be awarded on the basis of a combination of school-based assessment and an external assessment conducted by external examining body or ministry. Observation revealed that west African Examinations Council (WAEC) and National Examinations Council (NECO) are the two examining bodies in Nigeria that conduct senior school certificates examination. While NECO involves the school based continuous assessment scores in the final grading and certification of the students, WAEC appears to have simply jettisoned the inclusion of the school based continuous assessment scores in the final grading and certification of the students based probably on the issue of comparability of standard. The development of quality school based continuous assessment instrument cannot be taken for granted. It is often noticed that some lecturers construct tests which could be too difficult or too easy and hitherto, majority of testees will either fail or pass the test respectively. Denga (1987) also argued that there are classroom teachers who deliberately give too easy a test to his students to receive praise from the students while some other teachers give tests which are above the mental ability of the students to show that they are intelligent and tough. These go a long way to affect the standard of the continuous assessment scores.

Ojerinde (1985) doubted the reliability of the continuous assessment scores generated from different assessment instruments in the same subject from the different schools and hence asked whether the raw scores sent by each school could be relied upon.

Awuwoloye (1986) found high correlation between students' school based continuous assessment (SBCA) scores and school certificate examination scores in mathematics with values ranging form 0.71 to 0.86 which was attributed to the good quality staffing of the schools studied. Although, Abe (2006) found out that there was significant relationship among the internal assessment scores derived from Biology, Mathematics and English from the various school studied in Ekiti State, Nigeria but on applying Kurtosis as a statistical tool, he found that the school based continuous assessment (SBCA) scores from the schools were not normally peaked as the scores showed Platykurtic and Leptokurtic distribution as against the expected Mesokurtic distribution. However, Zinderman (1984) argued that it is advantageous for the schools to issue certificate independently as it is the case in the United States of America.

Perception (individual's belief or impression about something) have been described as one of the many correlates of attitude. Attitude on the other hand, is a psycho- personality construct involving the combination of belief and feelings which results in a disposition to respond favorably or unfavourable towards persons, group's ideals or objects. Hence Arijesuyo (2010) argued that "attitude are perceptions and involved emotional feelings or biases, evaluate judgment which predisposes one to act or behave in a certain way towards an idea, event or persons". In summary, attitude are important antecedents of action. While discussing the behavioral aspect of attitude, Arijesuyo (2010) described works behavior or attitudinal disposition to institution policy objective such as continuous assessment (CA) programme implementation in schools as a "function of the convictions and perceived relevance of such task to the organizational core-values among its major key actors".

Altitudinal perception may therefore be positive when individual response to task or program implementation is favorable and consequently show commitment to their duties as a result of their conviction about the relevance of such tasks to the organizational objective. On the other hand, negative (wrong) perception about the utility value of instructional programme may predispose non-challant attitude (apathy) among its principal stakeholders. As human beings, we tend to adjust to relevenat situations through the expression of appropriate attitude. Obviously teachers and the students constituted the key actors in CA score implementation in the school system. Therefore, this paper 
investigated the perception of lecturers and students about the relevance (utility-value) and the quality assurance of CA implementation in Nigeria University.

Alausa (2006) have defined continuous assessment as a mechanism or system whereby the final grading of a learner in knowledge, character and industry takes into account in a systematic way, all his performance during a given period of schooling such that the final grade becomes a crystallization of his whole course endeavour and performance. In another dimension, Umalusi (2004) defined continuous assessment as the systematic collection of marks or grades over a period of time and their aggregation into a final grade. Also, Ramoraka (2006) regarded continuous assessment as a method of ascertaining what a pupil gains from all his/her performance in tests, assignment project and other educational activities during a given period of term, year or during the entire period of an educational level. In his own submission, Sebying (2006) conceived of the CA as: "a mecehnism whereby the final grading of a students in cognitive, affective and psychomotor domains of behavior takes into account in a given systematic way of all his performance during a given period of schooling. Such and assessment involves the use of great variety of modes of evaluation for the purpose of guiding and improving the learning and performance of the student". From these definitions, and as noted by Ipaye (1982), Alausa (2006), Lumby (2006) and Ramoraka (2006) it has become evident that CA is predicated on the assumption that it is systematic, comprehensive, cumulative and guidance oriented. The cumulative nature of CA suggest that the assessment technique is growing as the child grows educationally and systematically reflecting changes and developments in responses to various courses, subject and projects. The comprehensive nature of CA also indicates that marks and grades could be awarded for a variety of in-and-out of class work, while the evaluation technique allows for 'the building of a cumulative judgment about the performance of each individual by use of test and non test data over a period of time' (Lumby, 2006). Studies have been carried out to determine the quality of academic success: cognitive and non-cognitive, acquired and required by University graduates in their different area of discipline in which employers of labour have been criticizing the quality of the Nigeria University output as being weak. This might not be among other factors unconnected with the evaluation methods in which lecturers CA quality is plying a major role. Gore et all (2011) found hat the school based continuous assessment scores for first year in English language and first and third year in Mathematics indicated positive skewness while the scores for second and third year in English language, second year in Mathematics and first, second and third year in Biology indicated negative skewness. The result confirmed the assertion of Alonge (2004) that there is need for uniformity of standard in education programme that involves continuous assessment practice which leads to certification. If the CA as it is being practiced in many universities in America, Europe and other parts of the world is producing high quality graduates including Nigerian students studding aboard, who have distinguished themselves in their various field of discipline and specializations, there is the need to improve on the existing standard and low reliability coefficient relationship between the CA scores and the end of semester examination scores in Nigeria Universities.

In line with the foregoing and in compliance with the (NPE 1981, 2004) policy guide lines on the implementation of CA, National University Commission (NUC) accordingly have directed all Nigerians universities to inbuilt continuous assessment as a component of the overall Cumulative Grade Point Average of each students in a knowm proportion. Following this directives, the general practices in all Nigerian universities is that, between (60-70) percent aggregate of the overall score (in each course) is assigned to the end of semester/course examination. The remaining (30-40) percent is usually devoted to (CA) in form of class test, take home exercises, assignment, term papers, project work or field trip as a matter of strict policy compliance. For instance, at the Federal University of Technology, Akure (FUTA) the relevant academic regulations on the administration of university examination provides that:

i. Final grade in courses shall comprise of continuous assessment and the end of course examinations in the form of theory, practical, studio, oral examination or SIWES or as otherwise specified.

ii. Assessment of student's achievement shall be continuous. The students shall be given at least three test on each course in a semester.

iii. continuous assessment shall carry a maximum mark of $40 \%$ and a minimum of $20 \%$ values or otherwise specified.

iv. The students shall be periodically informed of his / her standing in the course. (Federal University of Technology, Akure. (Compendium of Senate Decision P.79-80).

Arising from the above submission, the quality assurance of the operational strategies compatible with the implementation of CA in Nigerian universities should be measured in terms of the benchmark statements (standard performance indicators) as specified in the academic regulations of each university which includes; the quality of test with respect to its appropriateness, regularity, grading system, feedback from test scores to the learners and the moral correctness/ ethical integrity of CA operations by its key actors. 
Sebyeng (2006) allude to the problems militating against the quality assurance of CA regards to insufficient physical, human and financial resources to implements it, the increase in time and workload caused by the new assessment practices, and large class sizes affecting the ability of educators to teach and comply with the operational strategies compatible with CA implementations in schools. Also in recent studies Jonah-Eteli; (2008) and Etiga (2000) have expressed doubt about the credibility and quality assurance of the evaluation outcomes from the existing practices of CA in Nigerian Universities. Their findings revealed that many lecturers run foul of the acceptable standards of the continuous assessment programme implementation, and thus doubt about the credibility of the test scores. This ugly situation, the authors blamed on lack of commitment and devotion on the part of lecturers who are the principal actors in the programme implementation. Obviously attitude are reflected by the opinions or views that we hold about particular programme like CA implementation in the school system. Operating from the premise, this research seek to investigate the extent to which the existing practices of CA implementation in Nigeria university is congruent with the acceptable policy guidelines and the relevance of the CA as an educational package as perceived by lecturers and students.

\section{Hypothesis}

The following hypothesis guided the study:

Ho1: There is no significant relationship C A score and examination scores among the faculties in the university

Ho2: There is no significant difference in lecturers' and students' perception of the relevance of continuous assessment practice in Nigerian Universities.

Ho3: There is no significant difference in lecturers' and students' perception of the quality assurance of continuous assessment implementation in Nigeria universities.

\section{Methodology}

Design: The study is a descriptive research of the survey type.

Problem: The concern of the paper is the daunting in the standard of the

CA scores of the University lecturers and the end of the semesters examination scores. The problem therefore is to determine the worth and of the CA scores awarded by the university lecturers and it relationship with the end of semester examination scores as viewed by the university undergraduates and their lecturers.

Purpose The purpose is to investigate the relationship between the CA scores and the students examination scores as perceived by the students and their lecturers. It is significant as it aims at seeing how to set standard for the practice and its institutionalization among the Nigerian Universities

\section{Sample and sampling technique}

The samples consisted of 200 respondents select from four(4) existing degree awarding tertiary institution in Ondo and Ekiti state; namely: The Adekunle Ajasin University Akungba Akoko (AAUA), EkitiState University (EKSU) Ado Ekiti and Federal University of Technology Akure (FUTA). through simple random sampling technique. out of which 81 lecturers and 119 undergraduates students not below 300 level in their degree programme

\section{Instrument}

A-30 item questionnaire 4-likeirt scale titled Continuous Assessment Operational Rating Scale (CAORS) was used for this study. CAORS was an adapted version of continuous assessment perception scale (CAPS) developed by Adimula (1988). Lecturer and students perception ratings of the relevance and quality assurance of continuous assessments as currently practiced in the universities were the key issues measured in the four point rating scale. The instrument was pilot-tested for this study. The reliability co-efficient of 0.68 and 0.72 were obtained from the test re-test scores used to establish the reliability of the instrument.

\section{Data collection and analysis}

The administration of questionnaire was done by the researcher with the help of research assistants in the sampled institutions. Two hundred and fifty copies of the instrument were administered while two hundred and forty properly filled 
and returned were used for this study. The outcome of frequency counts of respondents on the basis of the variables tested were subjected to t-test statistics and the analysis of variance statistics.

The three hypotheses formulated for this study were tested at 0.05 alpha level confidence.

$\mathrm{H}_{1}$ There is no significant relationship between the $\mathrm{C}$ A scores among the faculties.

Table 3. Correlation matrix between the C A scores among the faculties Results

\begin{tabular}{|c|c|c|c|c|c|c|}
\hline Faculty & & 1 & 2 & 3 & 4 & 5 \\
\hline CA Vs Exam. Faculty of Art & $\mathrm{r} \quad 1$ & & $0.524^{*}$ & $0.743^{*}$ & 0.195 & $0.853^{*}$ \\
\hline CA Vs Exam. Faculty of Science & $\mathrm{r} 2$ & $0.524^{*}$ & & $0.611^{*}$ & $0.541^{*}$ & $-0.321^{*}$ \\
\hline CA Vs Exam. Faculty of Education & Ir 3 & $0.743^{*}$ & $0.611^{*}$ & & $0.370^{*}$ & 0.244 \\
\hline CA Vs Exam. Faculty of Social Sc. & $\mathrm{r} 4$ & 0.195 & $0.541^{*}$ & $0.370^{*}$ & & 0.224 \\
\hline CA Vs Exam. Faculty of Law. & $\mathrm{r} \quad 5$ & $0.853^{*}$ & $-.0 .321^{*}$ & 0.244 & 0.224 & \\
\hline
\end{tabular}

The table also indicated that the CAVs Exam Faculty of Art correlate positively with Faculty of Science 0.524 and Faculty of Law 0.853 but not with Faculty of Social Science.0.195. In the same way, Faculty of Science correlate positively with Education 0.611 and Social science 0.541 but negatively correlated with faculty of Law -0.21 . Faculty of Education correlate positively but very low with social science 0.370 but does not correlate with faculty of Law 0.244 . Finally there was no correlation between Faculty of Social science and Law 0.224 Hence there is no significant relationship between Art and Social Science, Law and Social science. There was a significant relationship between Art and Law, Science and Education and between Science and Social Science. The relationship between Science and Law was negative and lowERS

H03: There is no significance difference in the perception of lecturers' and students' of the quality assurance of continuous assessment implementation in Nigerian universities

Table 4: Means, Standard Deviation and t-test comparison of lecturers and students perception of the quality assurance of continuous assessment implementation in Nigerian universities.

\begin{tabular}{|c|c|c|c|c|c|c|}
\hline Variables & $N$ & $X$ & $S D$ & $D f$ & $t$-cal & $t$-crit \\
\hline Lecturers & 81 & 12.766 & 3.515 & 198 & 0.018 & 1.960 \\
\hline Students & 119 & 12.756. & 3.417 & & & \\
\hline
\end{tabular}

NS at 0.05 significance levels

From table 3and figure ii above, it was observed that a calculated t-value of 0.018 was obtained. This value is less than the critical t-value 1.960 at 0.05 of significance. This is an indication that there was no significant difference in the perception of lecturers and students about the quality assurance of continuous assessment as currently implemented in Nigerian universities, the hypothesis was therefore not rejected.

H04: There is no significance difference in lecturers' and students' perception of the relevance of continuous assessment implementation in Nigerian universities.

Table 5: Means, Standard Deviation and t-test comparison of lecturers and students perception of the relevance of CA practice

\begin{tabular}{|c|c|c|c|c|c|c|}
\hline Variables & $N$ & $X$ & $S D$ & $D f$ & $t$-cal & $t$-crit \\
\hline Lecturers & 81 & 15.123 & 3.690 & 198 & 0.892 & 1.960 \\
\hline Students & 119 & 15.124 & 3.491 & & & \\
\hline
\end{tabular}

NS at 0.05 significance levels

As indicated in table 2, the calculated t of 0.892 was less than the critical t-value of 1.96 at 0.05 alpha level of significance given degree of freedom of 198. in this regard, the null hypothesis which states that there is no significant difference in lecturers and students perception of the relevance of continuous assessment practice in Nigeria universities was no rejected. 


\section{Discussion}

In the foregoing analysis, the study examines whether university lecturers and their students were different in their perception of the relevance and the quality assurance of continuous assessment implementation in Nigerian universities. The findings showed that there no significantly difference in the lecturers and students perception of the relevance of continuous assessment as a mode of evaluation and a component of the Cumulative Grade Point Average of students overall academic performance in the University. This shows a compliance with the National Policy on Education (2004 Paragraph 7, emphasizing the importance of continuous assessment for the advancement of learners at all levels of Nigeria Education system. Every Institution, as guided by its governing body spells out the ratio of the Continuous Assessment. Continuous Assessment is usually either thirty percent (30\%) or forty percent (40\%) of each Semester total examination score of a hundred percent (100\%) taken in each subject every Semester. The scores derived cumulatively from all Semester examination results add up to the final grade for the certification of students. In every institution there are peculiarities in the exercise of continuous assessment. Although, lecturers/teachers are guided, hence they may have to comply with school regulation with respect to the period or time to administer the continuous assessment but by and large the exact time to administer the exercise, the mode (Test/Assignment).

The fact that, the students share similar view about the importance of the quality assurance of continuous assessment in Nigeria university system is a clear indication about the increase awareness the stakeholders have gained about the policy directives and seriousness with which lecturers and students have handled the implementation of policy guidelines on continuous assessment. it is no longer news to an averaged Nigerian students that continuous assessment constitutes an integral component of the overall end of course or semester Cumulative Grade Point Average. The conviction gained by the students about the importance of continuous assessment as a means of self monitoring of their academic progress and as a feedback mechanism to lecturers for the evaluation of their teaching methods, might have increased their commitment to the progressive evaluative technique and consequently influence the perception of teachers and student alike.

The findings of no significant difference in the perception of lecturers and students about the quality assurance of continuous assessment in the universities also imply positive indicator about the popularity and acceptability of the evaluative techniques among the key actors in the university system. Again, this finding seemed to have confirmed the views of Arijesuyo (2010) that many of the attitude and perceptual formation students acquire are influenced by the attitudes and behavior of their teachers and parents, so it might be that, students respondents in this study have acquire learned values from their lecturers which consequently shaped their perception in the same direction. In that case, it is not much of a surprise that lecturers and students in the context of this study share similar perception about the existing practices of continuous assessment policy implementation programme in Nigeria universities with regards to its relevance, quality and its institutionalization

\section{Conclusion and Recommendation}

Findings from this study have shown a general positive perception among lecturers and students about the relevance or utility-value of and the qualitative guarantee of continuous assessment programme implementation credibility in Nigeria universities. The high mean responses and the findings of no significant difference among respondents who are the key actors in the programme implementation clearly attest to this findings. In view of the crucial role CA is expected to play in the school system, it bemoans on the institutional administrators through the relevant government agencies to provide adequate supportive facilities to improve upon the current level of efficiency of the programme implementation for an enhanced quality assurance.

The fact that continuous assessment as a form of evaluation technique is cumulative, systematic and guidance oriented, it is excepted to serve as a self monitoring device for students' academic performance, as well as a means of progressive evaluation of pedagogy and learning outcomes for the lecturers through appropriated feedback mechanism. It should however be noted that, if on the contrary, prompt feedback from continuous assessment test are unduly delayed or out rightly denied, the inbuilt self advocated that, the Nigerian University Commission (NUC) should adopt a workable policy to ensure compliance with prompt release of test scores from continuous assessment to the students before the onset of corresponding semester examinations.

The ethical abuse of continuous assessment programme implementation by the lecturers as already noted in a study by Eteli (2008) should also be viewed seriously by the relevant supervisory organs. It is recommended that the percentage score for CA in science courses should be $60 \%$ of the $100 \%$ total semester scores. This is imperative as 
science courses required that students should be more proactive at presenting something tangible from their project or practical activities in terms of inventions, new discoveries that can lead to technical breakthrough in their area of specializations.. It is also therefore being recommended that individual university should set up a monitoring body to ensure that lecturers comply with the policy guideline that will guarantee the credibility, integrity and utility-value of continuous assessment programme in the universities.

\section{References}

Alausa, Y.A. (1996): Continuous assessment in our schools advantages and problems. Retrieved February 3, 2006, from http://ad.doubleclick.net//adi/snet/integarteddef;po

Alonge, M.F. (2004). Measurement and Evaluation in nd Education and Psychology 2 Edition, Ado-Ekiti, Adedayo Printing (Nig.) Ltd.

Etiga, S.A. (2000): Survey of the Opinion of Adminstrators, Students and Lecturers on the meaning rationale and practice of Continuous Assessment in Higher Institution in River State. An Unpublished B.Sc Project, River State University of Technology Nkopolu Port-Harcourt

Ezewu, E.E \& Okoye, N. N. (1986). Principles and practice of continuous assessment. Ibadan: Evans Publishers.

Federal Republic of Nigeria, (2004). National Policy on Education. (4th ed.). Lagos: NERDC .Government printers Press.

Gore L O ,Abe T O and Adodo S O (2011): Skewness and Comparability of School based Continuous Assessment Scores. imanager's Journal on School Educational Technology, Vol. 7 I No. 2 I September - November 2011

Ipaye, T. (1992). Continuous assessment in secondary schools: Implementation for guidance and counseling. Ilorin: Ilorin University Press.

Jonah- Eteli, W.A. (2008). Continuous Assessment, grading system, and feedback practice in Education Faculties and Quality Assurance in teacher education. Niger-Delta Journal of Education, continuous assessment Vol.1 (1), 10-8.

Joy du Plessis, Diane Prouty, Jane Schubert, Mona Habib and Eileen St. George (2003) Support for Continuous Assessment: A Practical Guide for Teachers from United States Agency for International Development (USAID)Bureau for Economic Growth, Agriculture and Trade Office of Education Contract ( 2003)

Lumby, G. (2006). Teaching towards outcome and its effect on assessment practices in a language, literacy and communication classroom. Retrieved June 19,2007, from http://www.up.ac.za

Ramoraka, N.J. (2006). Educators understanding of the premises underpinning outcomes based education and its impact on their classroom assessment practices. South Africa: University of Pretoria.

Sebyeng, M.M (2006). Outcome based assessment in Lephalale Circuit, L Limpompo Province. South-Africa: Tshwane University of Technology.

Umalusi, (2004). Council for Quality Assurance in General and Education and Further Education and Training. Draft policy for quality assurance assessment for the GETC and FET. Retrieved, June 8, 2008, from http://www.umalusi.org.za 